\title{
PENGARUH ABDOMINAL STRETCHING EXERCISE TERHADAP PENURUNAN DYSMENORRHEA
}

\author{
Yulita Elvira Silviani, Tita Rosnita, Buyung Keraman \\ Program Studi DIV Kebidanan STIKes Tri Mandiri Sakti Bengkulu, Hp: 082186619662 \\ vivielvira92@gmail.com
}

\begin{abstract}
ABSTRAK
Angka kejadian nyeri menstruasi (dysmenorrhea) di dunia sangat besar, rata-rata lebih dari 50\% perempuan disetiap Negara mengalami dysmenorrhea. Menurut data dari WHO, 2010 didapatkan angka kejadian sebesar 1.769 .425 jiwa (90\%) wanita mengalami dysmenorrhea dengan 10-15\% mengalami dysmenorrhea berat. Tujuan penelitian ini adalah untuk mengetahui pengaruh abdominal stretching exercise terhadap penurunan dysmenorrhea pada mahasiswa D III kebidanan STIKes Tri Mandiri Sakti. Metode penelitian yang digunakan adalah analitik kuantitatif metode praeksperimen dengan rancangan desain (one group pre test-post test) dalam satu kelompok dengan analisa uji Wilcoxon Signed Rank Test. Sampel pada penelitian ini sebanyak 19 responden diambil dengan teknik purposive sampling. Analisis penelitian ini menggunakan analisis univariat dan bivariat. Berdasarkan hasil penelitian didapatkan dari 19 responden yang mengalami dysmenorrhea, diperoleh rata-rata skala dysmenorrhea sebelum dilakukan senam 8,00 dan sesudah dilakukan senam diperoleh rata-rata 5,00 Berdasarkan hasil uji analisis terdapat signifikan nilai $p$-value $=0,000<\alpha=0,05$. Ada pengaruh abdominal stretching exercise terhadap penurunan dysmenorrhea pada mahasiswa D III kebidanan STIKES Tri Mandiri Sakti Bengkulu.
\end{abstract}

Kata Kunci: dysmenorrhea; abdominal stretching exercise; remaja putri

\section{THE EFFECT OF ABDOMINAL STRETCHING EXERCISE ON DYSMENORRHEA REDUCTION}

\begin{abstract}
The incidence of menstrual pain (dysmenorrheal) in the world is very large, on average more than $50 \%$ of women in each country experience dysmenorrheal. According to data from WHO, 2010 there was an incidence of 1,769,425 people (90\%) of women having dysmenorrheal with 10-15\% having severe dysmenorrheal. The purpose of this study was to determine the effect of abdominal stretching exercise gymnastics on the reduction of dysmenorrheal in students of Diploma of midwifery at STIKES Tri Mandiri Sakti students. The research method used in this quantitative analytical study was pre-experimental method with design design (one group pre-test post test) in one group. With paired simple T-test test analysis and Wilcoxon signed rank test to test the data with normal distribution. The samples in this study were 19 respondents and taken by purposive sampling technique. The analysis of this study used univariate and bivariate analysis with Wilcoxon Signed Rank Test. Based on the results of the study obtained from 19 respondents who experienced dysmenorrheal, obtained on average dysmenorrheal scale before doing 8.00 gymnastics and after doing gymnastics obtained an average of 5.00. Based on the results of the analysis there were significant $P$-value $=0,000<\alpha=005$ that there is an effect of abdominal stretching exercise on decreasing dysmenorrheal in Diploma midwifery students at level I and II at STIKES Tri MandiriSakti Bengkulu. The conclusion is that there is significant influence of abdominal Stretching to reduce dysmenorrheal pain in Diploma midwifery students of STIKES Tri Mandiri Sakti Bengkulu.
\end{abstract}

Keywords: abdominal stretching exercise; decreasing; female students 


\section{LATAR BELAKANG}

Angka kejadian nyeri menstruasi (dysmenorrhea) di dunia sangat besar, ratarata lebih dari $50 \%$ perempuan disetiap Negara mengalami dysmenorrhea. Menurut data dari WHO, 2010 didapatkan angka kejadian sebesar 1.769 .425 jiwa (90\%) wanita mengalami dysmenorrhea dengan 10-15\% mengalami dysmenorrhea berat. Di Indonesia angka kejadian dysmenorrhea sebesar 107.673jiwa (64,25\%), yang terdiri dari 59.671 jiwa (54,89\%) mengalami dysmenorrhea primer dan 9.496 jiwa $(9,36 \%)$ mengalami dysmenorrhea sekunder masalah dysmenorrhea setidaknya mengganggu 50\% wanita masa reproduksi dan $60-85 \%$ pada usia remaja yang mengakibatkan banyaknya absensi pada sekolah maupun kantor (Suparto, 2011).

Rasa nyeri timbul tidak lama sebelumnya atau bersama- sama dengan permulaan haid dan berlangsung untuk beberapa jam, walaupun pada beberapa kasus dapat berlangsung beberapa hari (Sukarni, 2013). Dysmenorrhea sangat berdampak pada remaja usia sekolah karena menyebabkan tergangugnya aktivitas sehari-hari. Jika seseorang siswi mengalami dysmenorrhea, aktivitas belajar mereka di sekolah terganggu dan hal ini membuat mereka tidak masuk sekolah. Seorang siswi yang mengalami dysmenorrhea tidak dapat berkonsentrasi belajar dan motivasi belajar akan menurun. Oleh karena itu dysmenorrhea pada remaja harus dapat ditangani dengan tindakan yang tepat untuk menghindari dampak negatif yang akan timbul (Sukarni 2013).

Senam dysmenorrhea merupakan aktivitas fisik yang dapat digunakan untuk mengurangi nyeri. Saat melakukan senam tubuh akan menghasilkan endorphin. Hormon endorphin yang semakin tinggi akan menurunkan atau meringankan nyeri yang dirasakan seseorang sehingga seseorang menjadi lebih nyaman, gembira, dan melancarkan pengiriman oksigen ke otot (Priandarini, 2010).

Latihan olahraga yang ringan sangat dianjurkan untuk mengurangi dysmenorrhea. Olahraga atau senam merupakan salah satu teknik relaksasi yang dapat digunakan untuk mengurangi nyeri. Hal ini disebabkan saat melakukan olahraga atau senam tubuh akan menghasilkan endorphin. Endorphin dihasilkan di otak dan susunan syaraf tulang belakang. Hormon ini dapat berfungsi sebagai obat penenang alami yang diproduksi otak sehingga menimbulkan rasa nyaman (Restianti, 2010).Dari hasil penelitian ternyata dysmenorrhea lebih sedikit terjadi pada olahragawati dibandingkan wanita yang tidak melakukan olahraga (Sumudarsono, 1998 dalam Puji, 2009).

Survei awal jumlah mahasiswa tingkat I kebidanan STIKES Tri Mandiri Sakti ada 92 orang kemudian telah dilakukan wawancara kepada 92 orang mahasiswa tingkat I Kebidanan didapatkan 46 mahasiswa mengalami dysmenorrhea yang mengalami dysmenorrhea ringan sebanyak 28 orang, dysmenorrhea sedang sebanyak 10 orang, dysmenorrhea berat sebanyak 7 orang dan 1 orang mengalami dysmenorrhea sangat Berat. Mahasiswa menyatakan bahwa untuk mengatasi nyeri haid tersebut dengan istirahat dan minum obat anti nyeri.

Tujuan penelitian ini untuk mengetahui pengaruh abdominal stretching exercise terhadap penuruan dysmenorrhea pada mahasiswa D III STIKES Tri Mandiri Sakti Bengkulu.

\section{METODE}

Penelitian ini dilakukan di STIKes Tri Mandiri Sakti Bengkulu pada Juni sampai dengan Agustus 20018. Penelitian ini menggunakan analitik kuantitatif metode pra eksperimen dengan rancangan desain one group pre test-post test. Populasi dalam 
penelitian ini mahasiswa tingkat I dan II STIKes Tri Mandiri Sakti Bengkulu dengan teknik purposive sampling didapatkan sejumlah 19 responden. Setelah mendapatkan 19 responden langkah pertama peneliti menanyakan tingkat nyeri dysmenorhea yang biasa dirasakan responden sebelumnya dengan menunjukkan format skala nyeri Numeric Rating Scale (NRS). Kemudian melakukan senam abdominal stretching exercise seminggu sebelum menstruasi dimana senam dilakukan sebanyak 3 kali seminggu, setelah menstruasi langkah berikutnya mengobservasi lagi mahasiswa pada hari ke 3 dan 4 menggunakan lembar lembar observasi. Senam dilakukan sesuai dengan standar Operasional Prosedur (SOP). Pengumpulan data dalam penelitian ini menggunakan data primer dengan lembar observasi untuk derajat dysmenorrhea menggunakan skala nyeri Numeric Rating Scale (NRS) . Data yang dikumpulkan dianalisis dengan menggunakan analisis univariat dan bivariate menggunkan uji Wilcoxon Signed Rank Test karena data berditribusi tidak normal.

\section{HASIL}

Gambaran karakteristik 19 responden yang diambil yaitu memiliki umur 19-20 tahun, memiliki siklus mestruasi teratur, tidak memiliki penyakit kronis atau kelainan yang berkaitan dengan sistem reproduksi. Analisis univariat digunakan untuk melihat gambaran tingkat dysmenorrhea sebelum dan sesudah abdominal stretching exercise (Tabel 1).

Tabel 1 Gambaran Tingkat Dysmenorrhea Pada Mahasiswa D III Kebidanan STIKES Tri Mandiri Sakti Bengkulu ( $n=19)$

\begin{tabular}{ccc}
\hline $\begin{array}{c}\text { Tingkat } \\
\text { Dysmenorrhea }\end{array}$ & Frekuensi & $\begin{array}{c}\text { Persentase } \\
\text { (\%) }\end{array}$ \\
\hline Sebelum perlakuan & & \\
Ringan & 0 & 0 \\
Sedang & 0 & 0 \\
berat & 16 & 84,2 \\
sangat berat & 3 & 15,8
\end{tabular}

\section{Lanjutan tabel 1}

\begin{tabular}{ccc}
\hline $\begin{array}{c}\text { Tingkat } \\
\text { Dysmenorrhea }\end{array}$ & Frekuensi & $\begin{array}{c}\text { Persentase } \\
\text { (\%) }\end{array}$ \\
\hline Sesudah perlakuan & & \\
Ringan & 1 & 5,26 \\
Sedang & 15 & 78,95 \\
Berat & 3 & 15,79 \\
Sangat berat & 0 & 0 \\
\hline
\end{tabular}

Tabel 1 menunjukkan bahwa mahasiswa sebelum dilakukan abdominal stretching exercise sebagian besar dengan tingkat nyeri berat sebanyak $16(84,2 \%)$, nyeri sangat berat $1(15,8 \%)$ dan tidak ada yang mengalami nyeri tingkat ringan-sedang. Sedangkan setelah dilakukan abdominal stretching exercise sebagian besar dengan tingkat nyeri sedang sebanyak 15 (78.95\%), nyeri berat $3(15,8 \%)$ dan tidak ada yang mengalami nyeri tingkat sangat berat .

Untuk mengetahui pengaruh pemberian abdominal stretching exercise maka dilakukan anlisi bivariat dengan Wilcoxon Signed Rank Test $P$-value dengan hasil pada tabel 2 sebagai berikut;

Tabel 2 Pengaruh Abdominal Stretching Exercise Terhadap Penurunan Dysmenorrhea Pada Mahasiswa D III Kebidanan STIKES Tri Mandiri Sakti Bengkulu ( $n=19)$

\begin{tabular}{lccccc}
\hline $\begin{array}{l}\text { Dysme- } \\
\text { norrhea }\end{array}$ & Mean & SD & Min & Max & $\begin{array}{c}\text { P. } \\
\text { value }\end{array}$ \\
\cline { 1 - 4 } $\begin{array}{l}\text { Sebelum } \\
\text { perlakuan }\end{array}$ & 8,05 & 1,079 & 7 & 10 & \\
\cline { 1 - 4 } $\begin{array}{l}\text { Sesudah } \\
\text { perlakuan }\end{array}$ & 5,47 & 1,307 & 3 & 8 & \\
\hline
\end{tabular}

Tabel 2 menunjukkan bahwa dari 19 mahasiswa yang mengalami dysmenorrhea sebelum dilakukan senam memiliki rata-rata skala nyeri 8,05 \pm SD 1,079 dan sesudah dilakukan senam memiliki rata-rata 5,47 \pm SD 1,307 dengan $p$ value $0.000(<0.05)$. Sehingga $\mathrm{Ho}$ ditolak dan $\mathrm{Ha}$ diterima, artinya ada pengaruh yang signifikan antara abdominal stretching exercise terhadap dysmenorrhea 
pada mahasiswa D III kebidanan STIKes Tri Mandiri Sakti Bengkulu.

\section{PEMBAHASAN}

Hasil penelitian menunjukkan sebelum dilakukan abdominal stretching exercise dari 19 mahasiswa kebidanan tingkat I dan II STIKES Tri Mandiri Sakti Bengkulu diperoleh rata-rata skala dysmenorrhea 8,05 diantaranya $16(84,2$ \%) mahasiswa yang mengalami dysmenorrhea dengan kategori nyeri berat dan 3 ( 15,8 \%) diantaranya mengalami nyeri sangat berat. Menurut Desti Ismarozi (2015) skala nyeri pada kelompok control diperoleh rata-rata 4,33 , nilai tertinggi 6 dan terendah 2.

Tabel 2 menunjukkan bahwa setelah dilakukan abdominal stretching exercise dari 19 mahasiswa yang mengalami dysmenorrhea diperoleh rata-rata skala nyeri 5,47 diantaranya mahasiswa yang mengalami skala nyeri nyeri ringan ada 1 (5,3 \%) mahasiswa, yang mengalami nyeri sedang ada 15 ( $7.9 \%)$ mahasiswa dan yang mengalami skala nyeri berat ada 3 ( 15,8 \%) mahasiswa kebidanan tingkat I dan || STIKES Tri MandiriSakti Bengkulu

Menurut Desti Ismarozi (2015) skala intensitas nyeri haid primer sesudah diberikan intervensi senam diperoleh rata-rata 3,07, skala nyeri terendah 1 dan skala nyeri tertinggi 5.

Berdasarkan hasil penelitian tentang pengaruh senam terhadap penurunan dysmenorrhea pada mahasiswa D III kebidanan tingkat I dan II STIKES Tri Mandiri Sakti Bengkulu dari 19 mahasiwa yang mengalami dysmenorrhea berat dan sangat berat dengan nilai $p$-value $0,000<0,05$. Bahwa ada pengaruh tentang abdominal stretching exercise terhadap penurunan dysmenorrhea pada mahasiswa D III kebidanan tingkat I dan II STIKES Tri Mandiri Sakti Bengkulu.

Sebelum dilakukan senam diperoleh ratarata skala nyeri 8,00 yang terdiri dari 16 mahasiswa yang skala nyeri dysmenorrhea berat dan 3 orang yang memiliki skala nyeri sangat berat. Setelah dilakukan abdominal stretching exercisedari 19 mahasiswa yang memiliki skala nyeri berat dan sangat berat memiliki perubahan diperoleh rata-rata 5,00.

Dari 16 mahasiswa yang skala nyeri dysmenorrhea berat menurun menjadi skala nyeri sedang, dan 1 mahasiswa yang memiliki skala nyeri ringan ini di karenakan adanya pengaruh lain selain senam yaitu mengkonsumsi obat-obatan dan dari 3 orang mahasiswa yang skala nyerinya sangat berat sebelum dilakukan senam setelah dilakukan senam ada penurunan walaupun sedikit dengan skala nyeri berat.

Hasil penelitian ini didukung penelitian Desti Ismaurozi tahun 2015 hasil uji Man Whitney menunjukkan $P$ Value $(0,016)<0,05$. Hal ini berarti terdapat perbedaan yang signifikan antara rata-rata nyeri haid primer remaja pada kelompok eksperimen yang diberikan senam dismenore dan kelompok control tanpa berikan senam dismenore, sehingga dapat disimpulkan bahwa pemberian intervensi senam dismenore efektif dalam menangani intesitas nyeri haid primer pada remaja.

Hasil penelitian ini juga sesuai dengan penelitian Salbiah tahun 2015 penurunan tingkat nyeri saat menstruasi melalui senam abdominal stretching exercaise. Skala sebelum perlakuan, skala nyeri 4-6 (sedang) dengan persentase $66,1 \%$ dan skala nyeri setelah perlakuan 1-3 (ringan) dengan persentase $89,3 \%$.

Menurut penelitian Weny Windastiwi, tahun Hasil penelitian menunjukkan bahwa intensitas nyeri dismenorea sebelum abdominal stretching exercise $75 \%$ responden mengalami dismenorea sedang dan terdapat 8 responden dismenorea berat. Intensitas nyeri dysmenorrhea setelah abdominal stretching exercise menunjukkan bahwa dari 48 
responden, tidak ada responden dengan nyeri dismenorea berat dan $85 \%$ mengalami dysmenorrhea sedang. Nilai $p$ value 0,000 dan nilai $z=4,689$ artinya ada pengaruh abdominal stretching exercise terhadap intensitas nyeri dismenorea.

Menurut penelitian Anita (2015) Pengaruh senam dysmenorrhea terhadap tingkat nyeri dysmenorrhea pada mahasiswa kebidanan semerter IV Poltekkes Majapahit Kabupaten Mojokerto Hasil penelitian didapatkan hasil senam dysmenorrhea berpengaruh pada tingkat penurunan nyeri dysmenorrhea pada kelompok perlakuan. Sehingga diharapkan bagi tenaga kesehatan dapat mengajarkan senam dysmenorrhea pada remaja dan pandangan dalam upaya untuk meningkatkan pengetahuan dalam mengatasi nyeri dysmenorrhea

Hal ini terjadi mengingat nyeri merupakan hal yang bersifat subjektif dan hanya seseorang yang mengalami kondisi tersebut yang dapat mendeskripsikan besarnya nyeri yang dirasakan. Sehingga akan berpengaruh terhadap penurunan skor intensitas nyeri pada masing -masing responden.

Olahraga atau senam merupakan salah satu teknik relaksasi yang dapat digunakan untuk mengurangi nyeri, hal ini disebabkan saat melakukan olahraga atau senam tubuh akan menghasilkan endorfin yang dihasilkan diotak dan sum-sum tulang belakang. Hormon endorfin berfungsi sebagai obat penenang alami sehingga menimbulkan rasa nyaman. (Anugroho, 2011).

Salah satu exercise yang dapat dilakukan untuk menurunkan intensitas nyeri haid (dismenore) adalah dengan melakukan latihan abdominal stretching. Latihan abdominal stretching yang dilakukan pada saat dismenore untuk meningkatkan kekuatan otot (Thermacare, 2010).

\section{KESIMPULAN DAN SARAN}

Ada pengaruh abdominal stretching exercise terhadap penurunan dysmenorrhea pada mahasiswa Diploma III kebidanan tingkat I dan II STIKES Tri Mandiri Sakti Bengkulu. Sehingga diharapkan bagi tenaga kesehatan dapat mengajarkan senam dysmenorrhea pada remaja dan pandangan dalam upaya untuk meningkatkan pengetahuan dalam mengatasi nyeri dysmenorrhea.

\section{REFERENSI}

Anita. (2015). Pengaruh Senam DysmenorrheaTerhadap Tingkat Nyeri Dysmenorrhea Pada Mahasiswa Kebidanan Semester IV Poltekes Majapahit Kabupaten Mojokerto.

Anugroho, D. W. (2011). Cara jitu mengatasi nyeri haid. yogyakarta: C.V.Andi Offset.

Annathayakeishka. (n.d.). Nyeri Haid. Diperoleh 08 juni 2014 dari http://forum.dudung.net.

Desti Ismarozi, S. U. (2015). Efektivitas Senam Dismenore Terhadap Penurunan Nyeri Haid Primer PAda Remaja. 825.

Puji, I. (2009). Efektivitas senam dismenore dalam mengurangi dismenore pada remaja putri di SMU N Semarang . Skripsi: Dipublikasikan.

Priandarini, S. d. (2010). Cara cerdas untuk sehat : Rahasia hidup sehat tanpa dokter. Jakarta: Transmedia.

Restianti, H. (2010). Mengenal Jenis Senam. Bogor: Quadra.

Salbiah. (2012). The Menstruasi Pain Level Decline By Abdominal Stretching

Suparto. (2011). Kehamilan Persalinan dan Nifas. Yogyakarta : NUha medika .

Sukarni, I. d. (2013). Buku Ajar Keperawatan Maternitas. Yogyakarta: Nuha Medika.

Weny Windastiwi, W. P. (2017). Pengaruh Abdominal Streching Exercise Terhadap Intensitas Nyeri Dismenore. Jurnal Kebidanan, 23. 